\title{
New Fluorenocrownophanes Containing Benzene or Biphenyl Fragments: Synthesis, Properties and Interaction with Paraquat
}

\author{
Tatyana I. Kirichenko, Alexander V. Lobach, Alexander Yu. Lyapunov, \\ Catherine Yu. Kulygina, Irene S. Yakovenko, and Nikolay G. Lukyanenko ${ }^{\circledR}$ \\ A.V. Bogatsky Physico-Chemical Institute, National Academy of Sciences of Ukraine, Odessa, 65080, Ukraine \\ ${ }^{\circledR}$ Corresponding author E-mail:ngl@farlep.net
}

\begin{abstract}
New fluorenocrownophanes containing fragments of 2,7-dioxyfluorene and hydroquinone or 4,4'-dioxybiphenyl linked by tri- and tetraethylene glycol residues were synthesized by palladium-catalyzed hydrogenation of the appropriate fluorenonocrownophanes. The formation of the pseudorotaxane type inclusion complexes of these ligands with paraquat was established by means of FAB mass spectrometry, ${ }^{1} H$ NMR and electronic spectroscopy. The crownophanes with larger ring formed the more stable complexes.
\end{abstract}

Keywords: Fluorenocrownophanes, fluorenonocrownophanes, hydrogenation, paraquat, pseudorotaxanes.

\section{Новые флуоренокраунофаны, содержащие фрагменты бензола или бифенила: синтез, свойства и взаимодействие с паракватом}

\author{
Т.И. Кириченко, А.В. Аобач, А.Ю. Аяпунов, Е.Ю. Кулыгина, И.С. Яковенко, \\ Н.Г. Аукьяненко ${ }^{\circledR}$ \\ Физико-химический институт имени А.В. Богатского Наџиональной академии наук Украины, Одесса, 65080, \\ Украина \\ @E-mail:ngl@farlep.net
}

\begin{abstract}
Восстановлением соответствующих флуоренонокраунофанов водородом в присутствии палладиевого катализатора получены новые флуоренокраунофаны, содержащие фрагменты 2,7-диоксифлуорена и гидрохинона или 4,4'-диоксибифенила, соединенные полиэфирными мостиками. Методами ББА-масс-спектрометрии, ${ }^{1} H$ ЯМР и электронной спектроскопии установлено образование псевдоротаксанов при взаимодействии этих лигандов с паракватом.
\end{abstract}

Ключевые слова: Флуоренокраунофаны, флуоренонокраунофаны, восстановление, паракват, псевдоротаксаны.

\section{Введение}

Краунофаны - циклофаны, ${ }^{[1-3]}$ в которых ароматические фрагменты соединены полиэфирными цепочками, являются одним из основных классов макроциклических рецепторов для ионных и нейтральных соединений. ${ }^{[4-8]} \mathrm{B}$ последние годы они привлекают особое внимание как исходные объекты для конструирования и синтеза супрамолекулярных систем типапсевдоротаксанов, ротаксанов и катенанов, ${ }^{[9-11]}$ которые являются базовыми элементами для создания молекулярных машин, переключателей, логических вентилей и других наноустройств. ${ }^{[2-16]}$

Известно относительно мало циклофанов и краунофанов с фрагментом флуорена в цикле. ${ }^{[17-24]}$
Подавляющее большинство исследований направлено на изучение внутримолекулярных взаимодействий ароматических фрагментов и спектральных свойств таких соединений. Практически отсутствуют сведения об их потенциальной способности выступать в роли хозяев для ионных и нейтральных молекул гостей. В то же время наличие в структуре краунофанов большой $\pi$-электронной системы флуорена наряду с другим $\pi$-донорным ароматическим фрагментом должно способствовать образованию ими комплексов включения с электронодефицитными молекулами.

В настоящем сообщении мы обсуждаем синтез, свойства и взаимодействие с паракватом новых флуоренокраунофанов, содержащих фрагменты 2,7-диок- 
сифлуорена и гидрохинона или 4,4'-диоксибифенила, соединенных полиэфирными мостиками.

\section{Экспериментальная часть}

Спектры ${ }^{1} \mathrm{H}$ и ${ }^{13} \mathrm{C}$ ЯМР регистрировали в растворах $\mathrm{CDCl}_{3}$ на приборах Varian VXR-300 $\left({ }^{1} \mathrm{H}\right)$ и Bruker Avance DRX 500 $\left({ }^{13} \mathrm{C}\right)$ с рабочими частотами 300 и 125.76 МГц соответственно, ${ }^{1} \mathrm{H}$ ЯМР спектры комплексов - в смеси $\mathrm{CD}_{3} \mathrm{CN}-\mathrm{CDCl}_{3}$ (4:3, об.). Масс-спектры с ионизацией электронным ударом регистрировали на масс-спектрометре MX-1321 (70 эВ, прямой ввод), ББА-масс-спектры - на масс-спектрометре VG 7070EQ (Хе, 8 кВ) в матрице 3-нитробензилового спирта. ЭСП записывали на спектрофотометре Specord M-40. Элементный анализ проводили на CHNS анализаторе EuroVector EA3000. Температуры плавления измерены в открытых капиллярах и не исправлены. Чистоту всех синтезированных веществ контролировали методом $\mathrm{TCX}\left(\mathrm{Al}_{2} \mathrm{O}_{3}\right.$ на стеклянных пластинах, проявление в парах йода). 1,4-Диметоксибензол и 4,4'-диметоксибифенил коммерчески доступны. Флуоренонокраунофаны 1a-г, ${ }^{[25,26]}$ и гексафторфосфат параквата 6·2PF ${ }_{6}^{[27]}$ получены, как описано ранее.

\section{Синтез}

Общая методика получения флуоренокраунофанов $2 a-2$. Через суспензию $10 \% \mathrm{Pd} / \mathrm{C}(0,1$ г) в смеси метанола с толуолом (3:1, 40 мл) пропускали при перемешивании ток водорода в течение 0,5 ч при $55-60{ }^{\circ} \mathrm{C}$, затем добавляли нагретый до $55-60{ }^{\circ} \mathrm{C}$ раствор соответствующего флуоренонокраунофана 1а-г $(0,5$ ммоль) в такой же смеси растворителей $(80$ мл). Продолжали перемешивание в токе водорода при этой температуре до полного превращения исходных соединений (TCX): 20 ч (2a), 5 ч (2б), 25 ч (2в), 25 ч (2г). Горячую реакционную массу фильтровали, осадок промывали горячим толуолом $(5 \times 20$ мл), объединенные фильтраты упаривали в вакууме и перекристаллизовывали остаток из подходящего растворителя.

$2,5,8,11,23,26,29,32$-Октаоксапентаичкло[31.2.2.1 $1^{12,16}$. $\left.1^{18,22} \cdot 0^{15,19}\right]$ нонатриаконта-1(35), 12(39), 13, 15, 18(38), 19, 21,33,36нонаен, 2a. Бесцветные кристаллы. Выход 0,201 г (75\%), т. пл. $153-153,5^{\circ} \mathrm{C}$ (из $\mathrm{CH}_{3} \mathrm{CN}$ ). Найдено, \%: С 69,53, Н 6,85. $\mathrm{C}_{31} \mathrm{H}_{36} \mathrm{O}_{8}$. Вычислено, \%: С 69,39, Н 6,76. m/z (ЭУ) $I_{\text {отн }} \%: 536[\mathrm{M}]^{+}(100)$, 224 (13), 198 (38), 45 (41). ${ }^{1} \mathrm{H}$ ЯМР $\left(\mathrm{CDCl}_{3}\right) \delta_{\mathrm{H}}$ м.д.: 7,55 (2Н, д, $J=8,4$ Гц, $\left.\mathrm{H}^{\mathrm{c}}\right), 7,07\left(2 \mathrm{H}\right.$, д, $J=2,2$ Гц, $\left.\mathrm{H}^{\mathrm{a}}\right), 6,97(2 \mathrm{H}$, дд, $J=8,4$, 2,2 Гц, $\left.\mathrm{H}^{\mathrm{b}}\right), 6,30\left(4 \mathrm{H}, \mathrm{c}, \mathrm{C}_{6} \mathrm{H}_{4}\right), 4,28-4,21\left(4 \mathrm{H}, \mathrm{м}, \mathrm{CH}_{2} \mathrm{O}\right), 3,94-$ 3,87 (4H, м, $\left.\mathrm{CH}_{2} \mathrm{O}\right), 3,80-3,66\left(12 \mathrm{H}, \mathrm{м}, \mathrm{CH}_{2} \mathrm{O}\right), 3,64-3,57$ (6H, м,

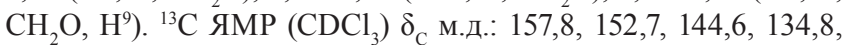
$119,6,114,9,114,0,111,6,71,2,70,9,70,0,69,9,67,8,67,6,37,0$.

22,5,8,11,14,26,29,32,35,38-Декаоксапентаиикло[37.2.2. $\left.1^{15,19} \cdot 1^{21,25} \cdot 0^{18,22}\right]$ пентатетраконта-1(41),15(45),16,18, 21(44), 22, 24,39,42-нонаен, 2б. Бесцветные кристаллы. Выход 0,250 г (80\%), т. пл. $109,5-110,5{ }^{\circ} \mathrm{C}$ (из ЕtOH). Найдено, \%: С 67,14, Н 7,19. $\mathrm{C}_{35} \mathrm{H}_{44} \mathrm{O}_{10}$. Вычислено, \%: С 67,29, Н 7,10. m/z (ЭУ) $I_{\text {отн. }} \%$ : $624\left[\mathrm{M}^{+}\right.$(100), 312 (4), 224 (6), 198 (15), 45 (36). ${ }^{1} \mathrm{H}$ ЯMP (CDCl $)$

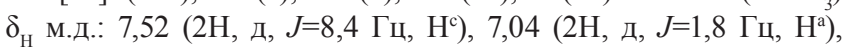
$6,92\left(2 \mathrm{H}\right.$, дд, $J=8,4,1,8$ Гц, $\left.\mathrm{H}^{\mathrm{b}}\right), 6,46\left(4 \mathrm{H}, \mathrm{c}, \mathrm{C}_{6} \mathrm{H}_{4}\right), 4,21-4,13(4 \mathrm{H}$, м, $\left.\mathrm{CH}_{2} \mathrm{O}\right), 3,94-3,88\left(4 \mathrm{H}, \mathrm{м}, \mathrm{CH}_{2} \mathrm{O}\right), 3,80-3,73\left(12 \mathrm{H}, \mathrm{м}, \mathrm{CH}_{2} \mathrm{O}\right)$,

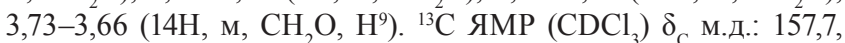
$152,8,144,5,134,8,119,6,114,9,113,5,111,6,71,0,70,8,70,7,70,4$, $69,9,69,7,68,0,67,6,37,0$.

$6,9,12,15,27,30,33,36-$ Октаоксагексаиикло $\left[35 \cdot 2 \cdot 2 \cdot 2^{2,5} \cdot 1^{16,20} \cdot 1^{22,26} \cdot 0^{19,23}\right]$ пен н та те тр акон та1(39),2,4,16(43),17,19,22(42),23,25,37,40,44-додекаен,

Бесцветные кристаллы. Выход 0,162 г (53\%), т. пл. 208,5$210,5{ }^{\circ} \mathrm{C}$ (из $\mathrm{CH}_{3} \mathrm{CN}$ ). Найдено, \%: С 72,62, Н 6,49. $\mathrm{C}_{37} \mathrm{H}_{40} \mathrm{O}_{8}$. Вычислено, \%: С 72,53, Н 6,58. m/z (ЭУ) $I_{\text {отн. }}$ \%: $612[\mathrm{M}]^{+}(100)$,
306 (5), 224 (7), 198 (50), 45 (79). ${ }^{1} \mathrm{H}$ ЯМР $\left(\mathrm{CDCl}_{3}\right) \delta_{\mathrm{H}}$ м.д.: 7,49 $\left(2 \mathrm{H}\right.$, д, $J=8,4$ Гц, $\left.\mathrm{H}^{\mathrm{c}}\right), 7,10\left(4 \mathrm{H}\right.$, д, $J=8,4$ Гц, $\left.\mathrm{H}^{2,2}, 6,66^{\circ}\right), 6,95-6,84$ $\left(4 \mathrm{H}, \mathrm{м}, \mathrm{H}^{\mathrm{a}}, \mathrm{H}^{\mathrm{b}}\right), 6,73\left(4 \mathrm{H}\right.$, д, $\left.J=8,4 \Gamma_{ц}, \mathrm{H}^{3,3,5,55^{\prime}}\right), 4,11-3,98(8 \mathrm{H}, \mathrm{м}$, $\left.\mathrm{CH}_{2} \mathrm{O}\right), 3,92-3,84\left(8 \mathrm{H}, \mathrm{m}, \mathrm{CH}_{2} \mathrm{O}\right), 3,77\left(8 \mathrm{H}, \mathrm{c}, \mathrm{CH}_{2} \mathrm{O}\right), 3,42(2 \mathrm{H}$, c, $\left.\mathrm{H}^{9}\right) .{ }^{13} \mathrm{C}$ ЯМР $\left(\mathrm{CDCl}_{3}\right) \delta_{\mathrm{C}}$ м.д.: 157,8, 157,7, 144,6, 134,8, 132,9, $127,1,119,6,115,0,113,8,111,1,71,1,71,0,69,8$ (2C), 67,7, 67,6, 36,8 .

6, 9, 12,15,18,30,33,36,39,42-Декаоксагексаиикло $\left[41.2 \cdot 2 \cdot 2^{2,5} \cdot 1^{19,23} \cdot 1^{25,29} \cdot 0^{22,26}\right]$ ген нен н такон та1(45),2,4,19(49),20,22,25(48),26,28,43,46,50-додекаен, 22. Бесцветные кристаллы. Выход 0,217 г (62\%), т. пл. 180,5$181,5{ }^{\circ} \mathrm{C}$ (из ЕtОН). Найдено, \%: С 70,20, Н 6,82. $\mathrm{C}_{41} \mathrm{H}_{48} \mathrm{O}_{10}$. Вычислено, \%: С 70,27, Н 6,90. m/z (ЭУ) $I_{\text {отн }}, \%: 700\left[\mathrm{M}^{+}(100)\right.$, 350 (5), 224 (10), 198 (24), 45 (72). ${ }^{1} \mathrm{H}$ ЯМР $\left(\mathrm{CDCl}_{3}\right) \delta_{\text {Н }}$ м.д.: 7,46 $\left(2 \mathrm{H}\right.$, д, $J=8,4$ Гц, $\left.\mathrm{H}^{\mathrm{c}}\right), 7,14\left(4 \mathrm{H}\right.$, д, $J=8,7$ Гц, $\left.\mathrm{H}^{2,2} ; 6,66^{2}\right), 6,93(2 \mathrm{H}$, д, $J=1,8$ Гц, $\left.\mathrm{H}^{\mathrm{a}}\right), 6,88\left(2 \mathrm{H}\right.$, дд, $J=8,4,1,8$ Гц, $\left.\mathrm{H}^{\mathrm{b}}\right), 6,73(4 \mathrm{H}$, д, $J=8,7$ Гц, $\left.\mathrm{H}^{3,3,5,5,5^{\prime}}\right), 4,09-4,04\left(4 \mathrm{H}, \mathrm{м}, \mathrm{CH}_{2} \mathrm{O}\right), 4,02-3,97\left(4 \mathrm{H}, \mathrm{m}, \mathrm{CH}_{2} \mathrm{O}\right)$, $3,93-3,87\left(8 \mathrm{H}, \mathrm{м}, \mathrm{CH}_{2} \mathrm{O}\right), 3,80-3,70\left(16 \mathrm{H}, \mathrm{m}, \mathrm{CH}_{2} \mathrm{O}\right), 3,56(2 \mathrm{H}, \mathrm{c}$,

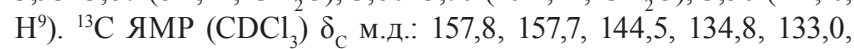
$127,2,119,6,114,6,113,5,111,1,70,9$ (2C), 70,7 (2C), 69,8, 69,7, $67,8,67,5,36,9$.

2,7-Диметокси-9Н-флуорен, 3. Через суспензию 10\% $\mathrm{Pd} / \mathrm{C}(0,1$ г) в метаноле (50 мл) пропускали при перемешивании ток водорода в течение 0,5 ч при $55-60{ }^{\circ} \mathrm{C}$. Затем прибавляли 2,7 -диметоксифлуоренон ${ }^{[28]}(0,15$ г, 0,625 ммоль) и продолжали перемешивание 2,5 часа. Горячую реакционную массу фильтровали, осадок промывали горячим метанолом $(3 \times 10$ мл), объединенные фильтраты упаривали в вакууме. Остаток перекристаллизовывали из бензола. Бесцветные кристаллы Выход 0,137 г (97\%), т. пл. $173{ }^{\circ} \mathrm{C}$. Найдено, \%: С 79,60, Н 6,41. $\mathrm{C}_{15} \mathrm{H}_{14} \mathrm{O}_{2}$. Вычислено, \%: С 79,62, Н 6,24. $\mathrm{m} / z$ (ЭУ) $I_{\text {отн. }} \%: 226$ $[\mathrm{M}]^{+}(100), 211(89) .{ }^{1} \mathrm{H}$ ЯМР $\left(\mathrm{CDCl}_{3}\right) \delta_{\mathrm{H}}$ м.д.: 7,56 (2H, д, $J=8,4$ Гц, $\left.\mathrm{H}^{\mathrm{c}}\right), 7,06\left(2 \mathrm{H}\right.$, д, $J=2,2$ Гц, $\left.\mathrm{H}^{\mathrm{a}}\right), 6,89(2 \mathrm{H}$, дд, $J=8,4,2,2$ Гц, $\left.\mathrm{H}^{\mathrm{b}}\right), 6,30\left(6 \mathrm{H}, \mathrm{c}, \mathrm{CH}_{3}\right), 3,81\left(2 \mathrm{H}, \mathrm{c}, \mathrm{H}^{9}\right)$.

\section{Результаты и обсуждение}

Наиболее удобным способом получения краунофанов, содержащих незамещенный по девятому положению фрагмент флуорена, на наш взгляд, является восстановление карбонильной группы флуоренонокраунофанов. Альтернативные способы получения малоприемлемы из-за легкого окисления производных флуорена при синтезе флуоренокраунофанов на их основе. В связи с этим синтез соединений 2а-г осуществляли восстановлением соответствующих флуоренонокраунофанов 1а-г ${ }^{[25,26]}$ водородом в присутствии $10 \%$ палладия на угле (Схема 1). Контроль степени превращения исходных соединений осуществляли методом TCX на стеклянных пластинах с закрепленным слоем нейтрального оксида алюминия.

При использовании в качестве растворителя метанола, этанола или 2-метилпропанола-1 реакцию проводили при 55, 70 и $100^{\circ} \mathrm{C}$ соответственно. При этом исходные краунофаны, за исключением 1б, полностью не растворялись и находились в виде суспензии. В этих условиях не удавалось достичь полного превращения исходных соединений за более чем 60 ч, а средние выходы продуктов реакции составляли: 37 (2a), 62 (2б), 23 (2в) и 27\% (2г). Полная конверсия исходных флуоренонокраунофанов 1а-г наблюдалась за 15-18 ч при проведении реакции в уксусной кислоте при температуре 55-60 ${ }^{\circ} \mathrm{C}$. Однако выходы целевых продуктов 2а-г были умеренными (20-45\%), из-за деструкции 
<smiles>CC(C)COc1ccc(-c2ccc(OCCCCOC(C)C)cc2)cc1</smiles>

1a-r

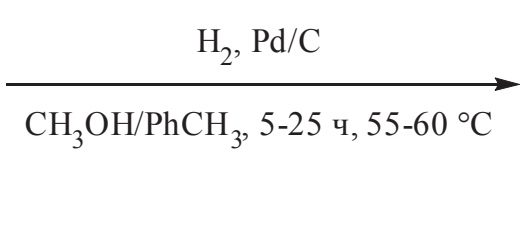

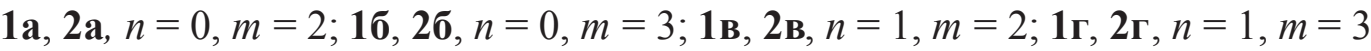

Схема 1. Синтез флуоренокраунофанов 2а-г.

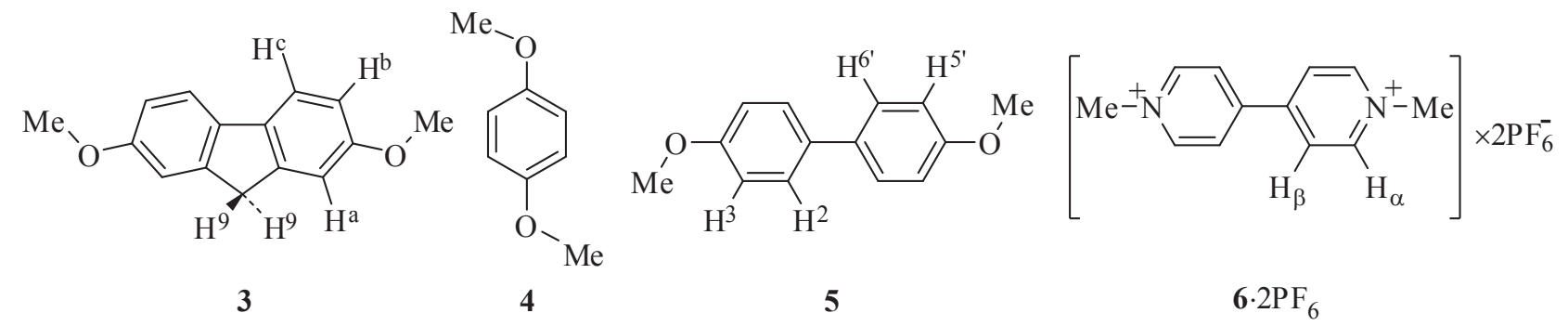

Схема 2.

краунофанов с образованием низкомолекулярных нециклических соединений, что подтверждено данными масс-спектрального анализа реакционной смеси.

Наиболее высоких выходов флуоренокраунофанов 2а-г при полном превращении исходных соединений за 5-25 ч при 55-60 ㄷ удалось достичь при использовании в качестве растворителя смеси метанол-толуол $3: 1$, позволяющей при повышенной температуре полностью растворять исходные соединения. После соответствующей обработки реакционной смеси и перекристаллизации из ацетонитрила или этанола целевые продукты выделяли в виде бесцветных кристаллов с выходами 75\% (2а), 80\% (2б), 53\% (2в) и 62\% (2г).

В ${ }^{1} \mathrm{H}$ ЯМР спектрах флуоренокраунофанов 2а,б регистрируется типичный для фрагментов олигоэтиленгликолей набор сигналов в области $\delta$ 4,29-3,55 м.д. Протоны флуорена представлены характерным набором сигналов в виде двух дублетов и дублета дублетов, протоны гидрохинона - в виде синглета, а бифенила - в виде двух дублетов. Вероятно, в результате экранирования противолежащим фрагментом флуорена сигналы протонов гидрохинона в соединениях 2a, $\mathbf{0}$ и бифенила в 2в,г испытывают заметные сдвиги в сильное поле по сравнению с их положениями в спектрах модельных соединений - 1,4-диметоксибензола 4 и 4,4'-диметоксибифенила 5 (Схема 2, Таблица 1). Величина этих сдвигов уменьшается с увеличением размеров цикла в парах соединений $\mathbf{2 a , \boldsymbol { 0 }}$ и $\mathbf{2 в , г , ~ ч т о ~ у к а з ы в а е т ~ н а ~ б о л е е ~ т е с н о е ~}$ взаимодействие ароматических фрагментов в меньших циклах. Величины химических сдвигов протонов флуорена $\mathrm{H}^{\mathrm{a}}, \mathrm{H}^{\mathrm{b}}$ и $\mathrm{H}^{\mathrm{c}}$, в сравнении с их положением в спектре 2,7-диметоксифлуорена 3, невелики и неоднозначны по знаку. Однако для сигналов $\mathrm{H}^{9}$ протонов наблюдаются существенные смещения в сильное поле. Синглетный

Таблица 1. Абсолютные $\left(\delta\right.$, м.д.) и относительные ( $\Delta \delta^{*}$, м.д.) химические сдвиги ароматических протонов** краунофанов $2 \mathrm{a}-\Gamma$ и модельных соединений $\mathbf{3 , 4}$ и $\mathbf{5}$ в $\mathrm{CDCl}_{3}$ при $298 \mathrm{~K}$.

\begin{tabular}{|c|c|c|c|c|c|c|c|c|c|c|c|c|c|c|}
\hline \multirow{2}{*}{ Соединение } & \multicolumn{2}{|c|}{$\mathrm{H}^{9}$} & \multicolumn{2}{|c|}{$\mathrm{H}^{\mathrm{a}}$} & \multicolumn{2}{|c|}{$\mathrm{H}^{\mathrm{b}}$} & \multicolumn{2}{|c|}{$\mathrm{H}^{\mathrm{c}}$} & \multicolumn{2}{|c|}{$\mathrm{C}_{6} \mathrm{H}_{4}$} & \multicolumn{2}{|c|}{$\mathrm{H}^{3,3,5,5}$} & \multicolumn{2}{|c|}{$\mathrm{H}^{2,2^{\prime}, 6,6^{\prime}}$} \\
\hline & $\delta$ & $\delta \Delta$ & $\delta$ & $\delta \Delta$ & $\delta$ & $\delta \Delta$ & $\delta$ & $\delta \Delta$ & $\delta$ & $\delta \Delta$ & $\delta$ & $\delta \Delta$ & $\delta$ & $\delta \Delta$ \\
\hline $2 a$ & $\sim 3,60 * * *$ & $-0,21$ & 7,07 & 0,01 & 6,97 & 0,08 & 7,55 & $-0,01$ & 6,3 & $-0,54$ & - & - & - & - \\
\hline $2 \sigma$ & $\sim 3,69 * * *$ & $-0,12$ & 7,04 & $-0,02$ & 6,93 & 0,04 & 7,52 & $-0,04$ & 6,46 & $-0,38$ & - & - & - & - \\
\hline $2 \mathrm{~B}$ & 3,42 & $-0,39$ & 6,9 & $-0,16$ & 6,9 & 0,01 & 7,49 & $-0,07$ & - & - & 6,73 & $-0,23$ & 7,10 & $-0,38$ \\
\hline $2 \Gamma$ & 3,56 & $-0,25$ & 6,93 & $-0,13$ & 6,88 & $-0,01$ & 7,46 & $-0,10$ & - & - & 6,73 & $-0,23$ & 7,14 & $-0,34$ \\
\hline 3 & 3,81 & - & 7,06 & - & 6,89 & - & 7,56 & - & - & - & - & - & - & - \\
\hline 4 & - & - & - & - & - & - & - & - & 6,84 & - & - & - & - & - \\
\hline 5 & - & - & - & - & - & - & - & - & - & - & 6,96 & - & 7,48 & - \\
\hline
\end{tabular}

* $\Delta \delta$ равна разности химических сдвигов соответствующих протонов в соединениях 2а, $\mathbf{6}$ и в $\mathbf{3}, \mathbf{4}$ и в соединениях $\mathbf{2}$ в,г и в $\mathbf{3}, \mathbf{5}$, соответственно.

**Обозначения протонов показаны на Схеме 2.

***Синглетный сигнал протонов $\mathrm{H}^{9}$ накладывается на мультиплетный сигнал $\mathrm{CH}_{2} \mathrm{O}$ групп. 
сигнал этих протонов, очевидно, обусловлен быстрым вращением ароматических фрагментов флуоренокраунофанов 2а-г в шкале времени ЯМР.

Паракват 6.2PF 6 и его производные (соли $N, N$ 'дизамещенного-4,4'-бипиридиния) являются одними из наиболее часто исследуемых электроноакцепторных гостей, образующих устойчивые комплексы включения с циклофанами и краунофанами. В частности, известно большое количество псевдоротаксанов - комплексов паракват-ионов с бензокраун-эфирами, криптандами, циклофанами и другими макроциклическими молекулами. ${ }^{[29-31]}$ Флуоренокраунофаны 2а-г, содержащие два $\pi$-электронодонорных ароматических фрагмента, по-видимому, также должны образовывать комплексы включения с паракват-дикатионом $\mathbf{6}^{2+}$.

Возможность образования таких комплексов и качественную оценку их относительной устойчивости проводили с помощью масс-спектрометрии в условиях бомбардировки быстрыми атомами (ББА), которая позволяет зафиксировать их образование. ${ }^{[32,33]}$ В масс-спектре раствора эквимольных количеств краунофанов 2а-г и десяти эквивалентов параквата 6.2PF ${ }_{6}$ в 3-нитробензиловом спирте наблюдаются пики молекулярных ионов 2а $-[\mathrm{M}+\mathrm{H}]^{+}(m / z=537), \mathbf{2 \sigma}-$ $[\mathrm{M}+\mathrm{H}]^{+}(m / z=625), \mathbf{2} \mathbf{B}-[\mathrm{M}+\mathrm{H}]^{+}(m / z=613), \mathbf{2} \mathbf{\Gamma}-[\mathrm{M}+\mathrm{H}]^{+}$ $(m / z=701)$, параквата 6.2PF $6-\left[\mathrm{M}-\mathrm{PF}_{6}\right]^{+}(\mathrm{m} / z=331)$ и пики, соответствующие потере гексафторфосфатаниона комплексами этих краунофанов с паракватом состава 1:1- $\left[\mathrm{M}-\mathrm{PF}_{6}\right]^{+}(m / z=867,955,943$, и 1031, соответственно). Такая спектральная картина характерна для большинства ротаксанов и псевдоротаксанов ${ }^{[34]}$ и свидетельствует об образовании достаточно устойчивых комплексов флуоренофанов 2а-г с паракватом 6.2PF , предположительно имеющих структуру псевдоротаксанов. Интенсивность пика комплексного иона $\left[\mathbf{2 6} \cdot \mathbf{6} \cdot \mathrm{PF}_{6}\right]^{+}$в 3 раза выше по сравнению с пиком $\left[\mathbf{2 a} \cdot \mathbf{6} \cdot \mathrm{PF}_{6}\right]^{+}$, а интенсивность пика $\left[\mathbf{2} \Gamma \cdot \mathbf{6} \cdot \mathrm{PF}_{6}\right]^{+}$выше чем $\left[\mathbf{2} \mathbf{8} \cdot \mathbf{6} \cdot \mathrm{PF}_{6}\right]^{+}$в 1,5 раза. Поскольку соотношение интенсивностей пиков комплексных ионов близких по структуре лигандов должно соответствовать их устойчивости, можно предполагать, что в условиях масс-спектрометрического эксперимента краунофаны, содержащие остатки тетраэтиленгликоля 2б и 2г образуют более стабильные, в сопоставлении с 2а и $\mathbf{2 в}$ комплексы с паракватом 6·2PF,

При прибавлении параквата $6 \cdot 2 \mathrm{PF}_{6}$ к растворам краунофанов 2а-г в ацетонитриле появляется интенсивная красная или оранжево-красная окраска. При этом в видимой области их электронных спектров поглощения (ЭСП) появляется широкая полоса с $\lambda_{\text {макс. }}$ $=\sim 479$, 475, 509 и 495 нм, соответственно (Рисунок 1). Появление этой полосы обусловлено образованием комплексов включения, стабилизированных донорноакцепторными взаимодействиями с переносом заряда $\pi$-донорных ароматических субъединиц циклофанов с $\pi$-акцепторным дипиридиниевым фрагментом параквата 6-2PF, , который находится в полости макроцикла. [34-36] Интенсивность этой полосы больше в спектрах флуоренофанов 2в,г в сравнении с наблюдаемым для

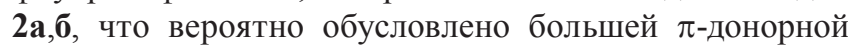
способностью фрагмента бифенила. Эта полоса более интенсивна в спектрах соединений с большим размером цикла в парах краунофанов 2а,б и 2в,г (Рисунок 1), что очевидно, является следствием большей устойчивости комплексов параквата $6 \cdot 2 \mathrm{PF}_{6}$ с соединениями 2 б и 2г относительно таких комплексов с 2а и 2в, соответственно.

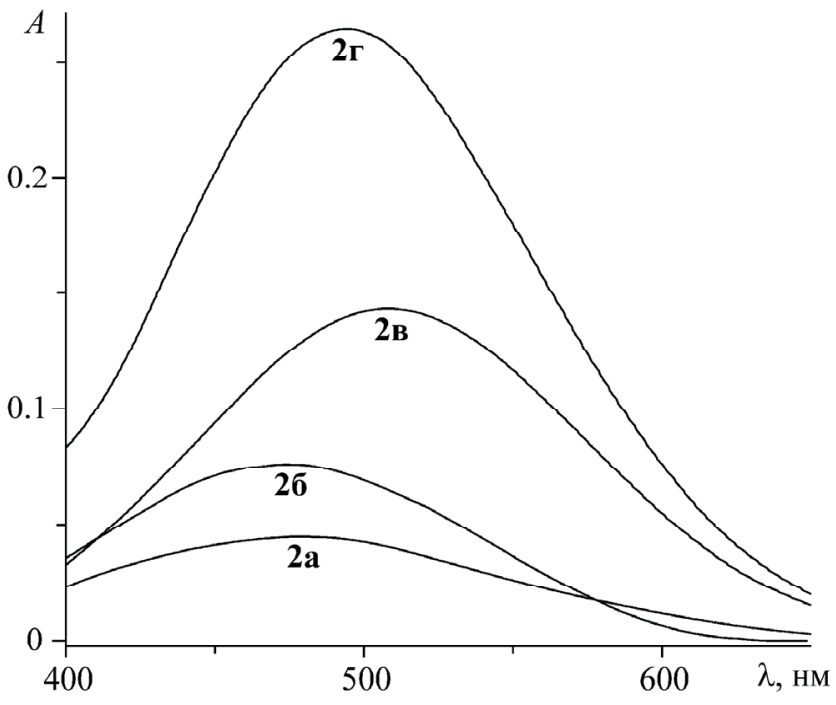

Рисунок 1. ЭСП смесей краунофанов 2а-г с паракватом 6.2PF ${ }_{6}$ в соотношениях 1:10 в ацетонитриле.

В ${ }^{1} \mathrm{H}$ ЯМР спектрах эквимольных смесей краунофанов 2а-г с паракватом 6-2PF 6 наблюдается сдвиг в сильное поле сигналов всех протонов ароматических фрагментов краунофанов и параквата по сравнению с их положением в спектрах индивидуальных соединений (Таблица 2, Рисунок 2). Это является характерным спектральным признаком образования комплексов включения, так как только в этом случае возможно взаимное

Таблица 2. Величины сильнопольных сдвигов (- $\Delta \delta$ м.д.) сигналов ароматических протонов краунофанов 2а-г и параквата 6.2PF ${ }_{6}$ в ${ }^{1} \mathrm{H}$ ЯМР спектрах их эквимольных смесей в $\mathrm{CD}_{3} \mathrm{CN}-\mathrm{CDCl}_{3}, 4: 3$ при $298 \mathrm{~K}$.

\begin{tabular}{|c|c|c|c|c|c|c|c|c|c|}
\hline \multirow{2}{*}{ Соединение } & \multicolumn{9}{|c|}{$-\Delta \delta$, м.д. } \\
\hline & $\mathrm{H}^{9}$ & $\mathrm{H}^{\mathrm{a}}$ & $\mathrm{H}^{\mathrm{b}}$ & $\mathrm{H}^{\mathrm{c}}$ & $\mathrm{C}_{6} \mathrm{H}_{4}$ & $\mathrm{H}^{3,3^{\prime}, 5,5^{\prime}}$ & $\mathrm{H}^{2,2^{2}, 6,6^{\prime}}$ & $\mathrm{H}_{\alpha}$ & $\mathrm{H}_{\beta}$ \\
\hline $2 a$ & $\sim 0,06^{*}$ & 0,07 & 0,04 & 0,08 & 0,02 & - & - & 0,05 & 0,18 \\
\hline $2 \sigma$ & $\sim 0,07^{*}$ & 0,14 & 0,12 & 0,15 & 0,12 & - & - & 0,21 & 0,42 \\
\hline 2B & 0,08 & 0,07 & 0,10 & 0,11 & - & 0,05 & 0,05 & 0,21 & 0,34 \\
\hline $2 \Gamma$ & 0,16 & 0,15 & 0,08 & 0,11 & - & 0,07 & 0,07 & 0,21 & 0,30 \\
\hline
\end{tabular}

*Точное значение $\Delta \delta$ определить трудно, так как в спектрах краунофанов 2a, $\mathbf{0}$ сигнал протонов $\mathrm{H}^{9}$ накладывается на сигнал $\mathrm{CH}_{2} \mathrm{O}$ групп. 


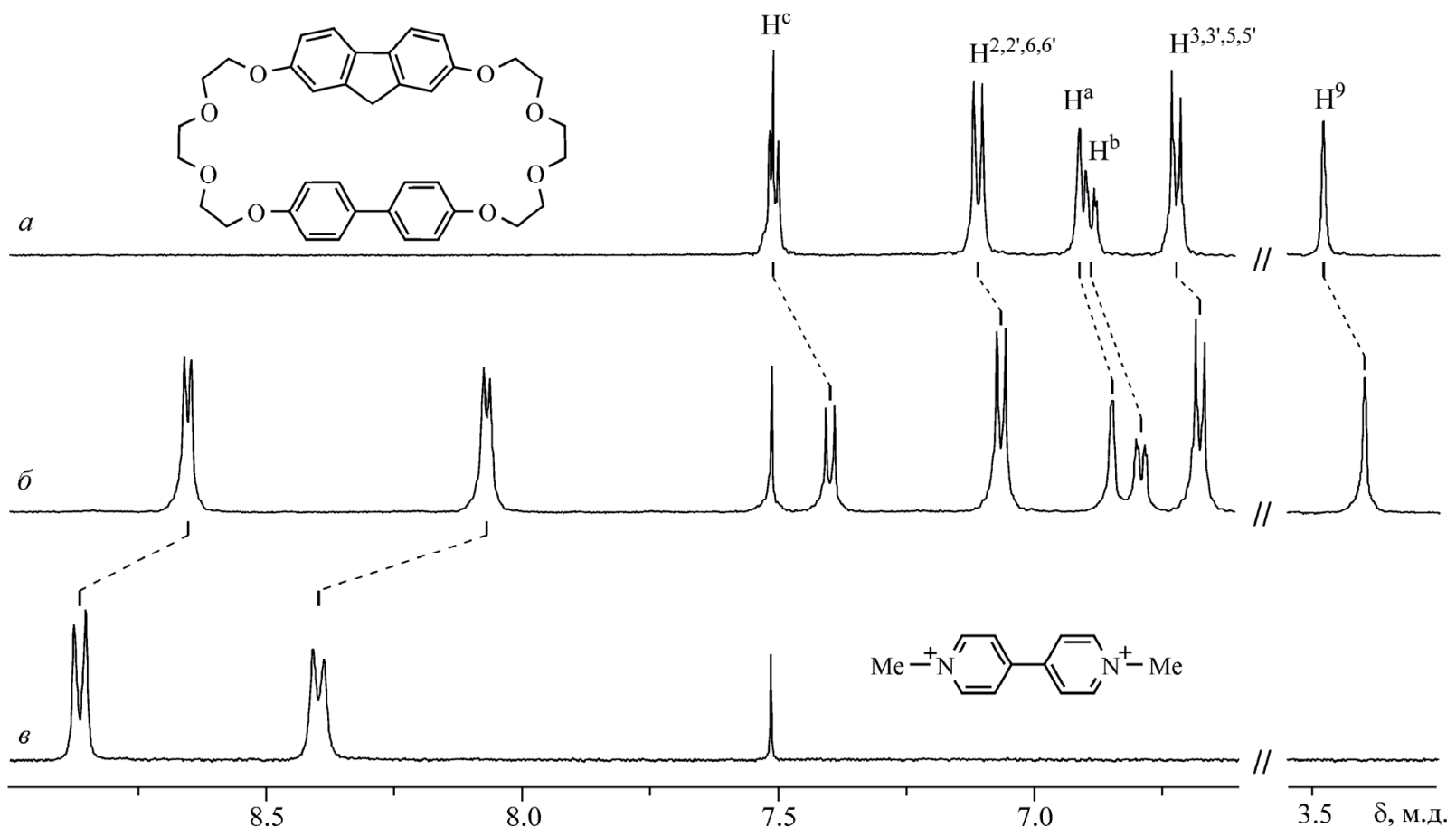

Рисунок 2. Фрагменты ${ }^{1} \mathrm{H}$ ЯМР спектров краунофана 2в (а), его эквимольной смеси с паракватом 6·2PF 6 (б) и параквата 6.2PF 6 (в) в смеси $\mathrm{CD}_{3} \mathrm{CN}-\mathrm{CDCl}_{3} 4: 3$.

экранирование двух ароматических фрагментов краунофана и пиридиниевых циклов параквата. ${ }^{[34]}$

Так как величина сдвига сигналов параквата в сильное поле фактически отражает степень его участия в донорно-акцепторных взаимодействиях с $\pi$-донорными ароматическими субъединицами циклофанов, можно считать, что величина сдвига сигналов протонов $\mathrm{H}_{\alpha}$ и $\mathrm{H}_{\beta}$ молекулы параквата для близких по структуре комплексов в первом приближении пропорциональна их устойчивости. Отсюда следует, что краунофан 2б образует с паракватом более устойчивый комплекс, чем 2a, а комплексы краунофанов 2в и 2г имеют схожее строение и сравнимую устойчивость. Это предположение хорошо согласуется с результатами ББА-масс-спектрометрии и данными ЭСП.

Отметим, что при включении параквата во внутримолекулярную полость краунофанов 2а-г можно было ожидать проявление сигнала $\mathrm{H}^{9}$ протонов флуорена в виде дублета, как результат их неэквивалентности из-за анизотропного влияния параквата. Вероятно, наблюдаемый в ${ }^{1} \mathrm{H}$ ЯМР спектрах комплексов 2а. ${ }^{2+}, \mathbf{2 \sigma} \cdot \mathbf{6}^{2+}$, $\mathbf{2 B}^{2} \cdot \mathbf{6}^{2+}$ и $\mathbf{2} \boldsymbol{\Gamma} \cdot \mathbf{6}^{2+}$ единственный синглетный сигнал этих протонов свидетельствует о реализации такой структуры комплексов, в которой они расположены вне зоны влияния параквата.

Очевидно, что различия в спектральном поведении и устойчивости комплексов циклофанов 2а-г с паракватом 6·2PF 6 определяются их структурой. Однако нам не удалось получить монокристаллы этих комплексов пригодные для рентгеноструктурного исследования. В связи с этим был осуществлен поиск оптимальных структур таких комплексов по методу статистической механики Monte-Carlo (силовое поле MMFF94, программный пакет Spartan'06 [37]).

Выявленные в результате расчета наиболее выгодные структуры комплексов флуоренофанов 2а-г с паракватом представлены на Рисунке 3.

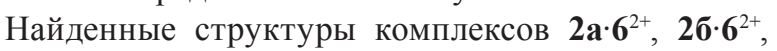

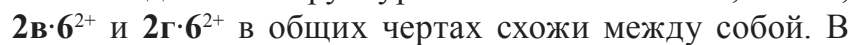
каждой из них паракват включен во внутримолекулярную полость циклофана. Однако если в комплексе

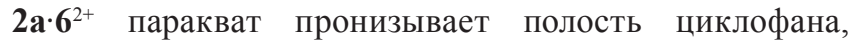
образуя типичный псевдоротаксан, то в комплексах краунофанов с большим размером цикла он стремится
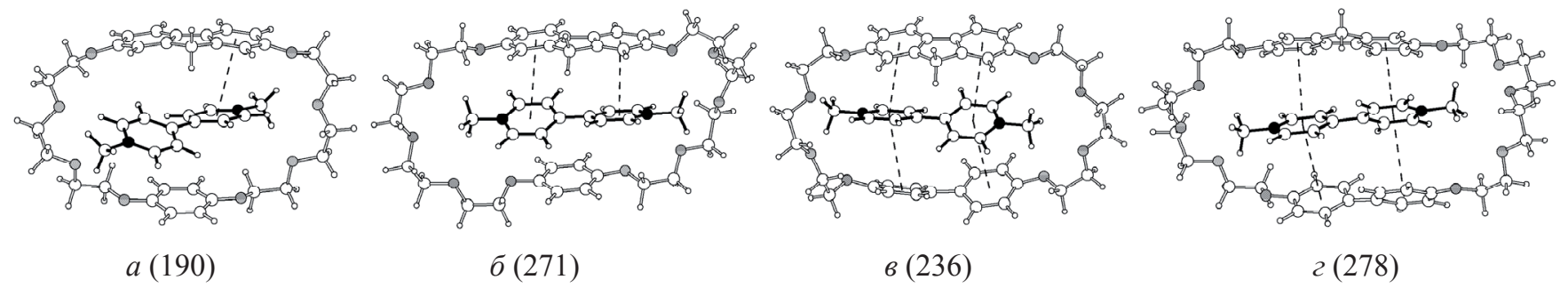

Рисунок 3. Рассчитанные структуры и энергии стабилизации (- $\Delta E$, кДж/моль) комплексов краунофанов 2а $(a), \mathbf{2 \sigma}(\sigma), 2$ в $(8)$ и 2г (2) с паракват-дикатионом $\mathbf{6}^{2+}$. Величина $\Delta E$ является разностью между энергией комплекса и суммой энергий свободных хозяина и гостя $\left(\Delta E=E_{\text {комплекс }}-E_{\text {хозяин }}-E_{\text {гость }}\right)$. 
расположиться вдоль длинной оси макроцикла, оптимизируя, таким образом, взаимодействия с их ароматическими фрагментами. В комплексе $\mathbf{2 a} \cdot \mathbf{6}^{2+}$ только один пиридиниевый цикл паракват-дикатиона взаимодействует с фенильным кольцом флуорена, в то время как в комплексах 2б.6 ${ }^{2+}, \mathbf{2 в} \cdot \mathbf{6}^{2+}$ и 2 г $\mathbf{6}^{2+}$ в таких взаимодействиях участвуют оба пиридиниевых цикла параквата. Фрагмент гидрохинона в комплексах 2а.6 ${ }^{2+}$ и $\mathbf{2 0} \cdot 6^{2+}$ практически не взаимодействует с паракватом. Однако в комплексах 2в·6 ${ }^{2+}$ и 2 г $\mathbf{6}^{2+}$ в донорно-акцепторных $\pi-\pi$ взаимодействиях с паракватом задействованы фенильные кольца как флуорена, так и бифенила. Как следует из величин энергий стабилизации комплексов (Рисунок 3) краунофаны 2б и 2г образуют более стабильные комплексы, чем их меньшие аналоги 2а и 2в, соответственно. В целом результаты расчета хорошо согласуются с результатами ББА-масс-спектрометрии, данными ЭСП и ${ }^{1} \mathrm{H}$ ЯМР спектроскопии.

\section{Выводы}

В заключение отметим, что нами впервые получены флуоренокраунофаны, включающие фрагмент 2,7-диоксифлуорена и гидрохинона или бифенила. Комплексом спектральных методов и компьютерным молекулярным моделированием показано, что они образуют комплексы включения при взаимодействии с гексафторфосфатом параквата 6.2PF. Это указывает на перспективность применения их в качестве рецепторов электронодефицитных молекул и синтеза на их основе супрамолекулярных структур типа ротаксанов и катенанов.

\section{Список литературы}

\section{References}

1. Diederich F. Cyclophanes. Cambridge: The Royal Society of Chemistry, 1991. $313 \mathrm{p}$.

2. Vögtle F. Cyclophane Chemistry. Chichester: J. Wiley \& Sons, 1993. 510 p.

3. Cram D.J., Cram J.M. Container Molecules and Their Guests. Cambridge: The Royal Society of Chemistry, 1994. 223 p.

4. Inokuma S., Sakaki S., Nishimura J. Top. Curr. Chem. 1994, 172, 87-118.

5. Tsuzuki S., Houjou H., Nagawa Y., Goto M., Hiratani K. J. Am. Chem. Soc. 2001, 123, 4255-4258.

6. Fis M.J., Seiler P., Muslinkina L.A., Badertscher M., Pretsch E., Diederich F., Alvarado R., Echegoyen L., Nunez I.P. Helv. Chim. Acta. 2002, 85, 2009-2055.

7. Hartley J.H., James T.D., Ward C.J. J. Chem. Soc., Perkin Trans. I. 2000, 3155-3184.

8. Xu J., Lai Y.-H., Wang W. Org. Lett. 2003, 5, 2781-2784.

9. Lehn J.-M. Supramolecular Chemistry: Concepts and Perspectives. Weinheim: Wiley-VCH, 1995. $281 \mathrm{p}$.
10. Steed J.W., Atwood J.L. Supramolecular Chemistry, $2^{\text {nd }}$ ed. New York: Wiley, 2009. 990 p.

11. Molecular Catenanes, Rotaxanes and Knots (Sauvage J.-P., Dietrich-Buchecker C.O., Eds). Weinheim: Wiley-VCH, 1999. $368 \mathrm{p}$.

12. Molecular Switches (Feringa B.L. Ed.). Weinheim: Wiley$\mathrm{VCH}, 2001.476 \mathrm{p}$.

13. Balzani V., Credi A., Raymo F.M., Stoddart J.F. Angew. Chem. Int. Ed. 2000, 39, 3348-3391.

14. Balzani V., Venturi M., Credi A. Molecular Devices and Machines - A Journey into the Nano World. Weinheim: Wiley-VCH, 2003. 511 p.

15. Balzani V., Credi A., Ferrer B., Silvi S., Venturi M. Top. Curr. Chem. 2005, 262, 1-27.

16. Loeb S. J. Chem. Soc. Rev. 2007, 36, 226-235.

17. Haenel M. W., Irngartinger H., Krieger C. Chem. Ber. 1985, 118, 144-162.

18. Schweitzer D., Haenel M. W. Chem. Ber. 1985, 118, 163-175.

19. Tsuge A., Nada R., Moriguchi T., Sakata K. J. Org. Chem. 2001, 66, 9023-9025.

20. Tsuge A., Ueda Y., Araki T., Moriguchi T., Sakata K., Koya K., Mataka S., Tashiro M. J. Chem. Res. (S) 1997, 168-169.

21. Apel S., Nitsche S., Beketov K., Seichter W., Seidel J., Weber E. J. Chem. Soc. Perkin Trans. 2 2001, 1212-1218.

22. Nehlig A., Kaufmann G., Asfari Z., Vicens J. Tetrahedron Lett. 1999, 40, 5865-5868.

23. Tsuge A., Yamasaki T., Moriguchi T., Matsuda T., Nagano Y., Nago H., Mataka S., Kajigaeshi S., Tashiro M. Synthesis 1993, 205-206.

24. Rajakumar P., Kanagalatha R. Tetrahedron Lett. 2007, 48, 2761-2764.

25. Luk'yanenko N.G., Kirichenko T.I., Lyapunov A.Yu., Kulygina E.Yu., Mazepa A.V. Zh. Org. Khim. 2009, 45, 313320 (in Russ.) [Russ. J. Org. Chem. 2009, 45, 304-311 (Engl. transi.)].

26. Luk'yanenko N.G., Kirichenko T.I., Lyapunov A.Yu., Kulygina E.Yu. Izv. Ross. Acad. Nauk, Ser. Khim. 2008, 57, 1665-1670 (in Russ.).

27. Manjula A., Nagarajan M. Arkivoc 2001, 165-183.

28. Barnes N.A., Faessinger R.W. J. Org. Chem. 1961, 26, 45444548.

29. Badjic J.D., Cantrill S.J., Stoddart J.F. J. Am. Chem. Soc. 2004, 126, 2288-2289.

30. Credi A., Dumas S., Silvi S., Venturi M., Arduini A., Pochini A., Secchi A. J. Org. Chem. 2004, 69, 5881-5887.

31. Kwangyul M., Kaifer A.E. Org. Lett. 2004, 6, 185-188.

32. Vincenti M. J. Mass Spectrom. 1995, 30, 925-939.

33. Schalley C.A. Int. J. Mass Spectrom. 2000, 194, 11-39.

34. Amabilino D.B., Stoddart J.F. Chem. Rev. 1995, 95, 27252828.

35. Asakawa M., Ashton P.R., Dehaen W., L’abbé G., Menzer S., Nouwen J., Raymo F.M., Stoddart J.F., Tolley M. S., Toppet S., White A.J.P., Williams D.J. Chem. Eur. J. 1997, 3, 772787.

36. Ballardini R., Balzani V., Di Fabio A., Gandolfi M.T., Becher J., Lau J., Nielsen M.B., Stoddart J.F. New J. Chem. 2001, 25, 293-298.

37. Spartan'06, Wavefunction, Inc. Irvine, CA. 